\title{
The Energy Sensor AMPK: Adaptations to Exercise, Nutritional and Hormonal Signals
}

\author{
Benoit Viollet
}

\begin{abstract}
To sustain metabolism, intracellular ATP concentration must be regulated within an appropriate range. This coordination is achieved through the function of the AMP-activated protein kinase (AMPK), a cellular "fuel gauge" that is expressed in essentially all eukaryotic cells as heterotrimeric complexes containing catalytic $\alpha$ subunits and regulatory $\beta$ and $\gamma$ subunits. When cellular energy status has been compromised, AMPK is activated by increases in AMP:ATP or ADP:ATP ratios and acts to restore energy homeostasis by stimulating energy production via catabolic pathways while decreasing non-essential energy-consuming pathways. Although the primary function of AMPK is to regulate energy homeostasis at a cellautonomous level, in multicellular organisms, the AMPK system has evolved to interact with hormones to regulate energy intake and expenditure at the whole body level. Thus, AMPK functions as a signaling hub, coordinating anabolic and catabolic pathways to balance nutrient supply with energy demand at both the cellular and whole-body levels. AMPK is activated by various metabolic stresses such as ischemia or hypoxia or glucose deprivation and has both acute and long-term effects on metabolic pathways and key cellular functions. In addition, AMPK appears to be a major sensor of energy demand in exercising muscle and acts both as a multitask gatekeeper and an energy regulator in skeletal muscle. Acute activation of AMPK has been shown to promote glucose transport and fatty acid oxidation while suppressing glycogen synthase activity and protein synthesis. Chronic activation of AMPK induces a shift in muscle fiber type composition, reduces markers of muscle degeneration and enhances muscle oxidative capacity potentially by stimulating mitochondrial biogenesis. Furthermore, recent evidence demonstrates that AMPK may not only regulate metabolism during exercise but also in the recovery phase. AMPK acts as a molecular transducer between exercise and insulin signaling and is
\end{abstract}

\footnotetext{
B. Viollet $(\triangle)$

Institut Cochin, INSERM, U1016, Paris, France

CNRS, UMR8104, Paris, France

Université Paris Descartes, Sorbonne Paris cité, Paris, France

e-mail: benoit.viollet@inserm.fr

B. Spiegelman (ed.), Hormones, Metabolism and the Benefits of Exercise, 
necessary for the ability of prior contraction/exercise to increase muscle insulin sensitivity. Based on these observations, drugs that activate AMPK might be expected to be useful in the treatment of metabolic disorders and insulin resistance in various conditions.

\section{Introduction}

One fundamental parameter that living cells need to sustain essential cellular functions is the maintenance of sufficiently high level of ATP. Thus, cell survival is dependent on a dynamic control of energy metabolism when ATP demand needs to remain in balance with ATP supply. If ATP consumption exceeds ATP production, the ADP:ATP ratio rises, but this is converted into an even larger rise in AMP:ATP ratio due to the reaction catalyzed by adenylate kinase (2ADP $\leftrightarrow$ ATP + AMP). If the reaction is at equilibrium, the AMP:ATP ratio will vary as the square of the ADP:ATP ratio, making increases in AMP a more sensitive indicator of energy stress than decreases in ATP or increases in ADP. On this basis, the cell requires an efficient energy sensory mechanism based on the detection of the ratios of ADP:ATP or AMP:ATP. Such a system has been identified as the AMP-activated protein kinase (AMPK), a heterotrimeric serine/threonine kinase conserved throughout eukaryote evolution (Hardie et al. 2012). The primary function of AMPK is to monitor changes in the intracellular level of ATP and maintain energy stores by reprogramming metabolism through an increase in the rate of catabolic ATP-producing pathways and a decrease in the rate of nonessential anabolic ATP-utilizing pathways. These regulatory features are initiated by the phosphorylation of key metabolic enzyme as well as transcription factors for both short-term effects and long-range regulatory actions for a better response to future challenges. Although the AMPK system originally evolved to regulate energy homeostasis in a cell-autonomous manner, in multicellular organisms, its role has adapted to integrate stress responses such as exercise as well as nutrient and hormonal signals to control food intake, energy expenditure, and substrate utilization at the whole body level (Hardie 2014). Activation of AMPK is triggered by a diverse array of external (e.g., exercise, hormones, nutrients) and internal signals (e.g., AMP/ATP and ADP/ATP ratios) and has been implicated in the regulation of a wide range of biochemical pathways and physiological processes. As a consequence, AMPK has stimulated much interest due to its potential impact on metabolic disorders. The aim of this chapter is to discuss the possible role of AMPK in the adaptations to exercise, nutrient and hormonal signals and its potential as a therapeutic drug target, mimicking the beneficial effects of exercise. 
A

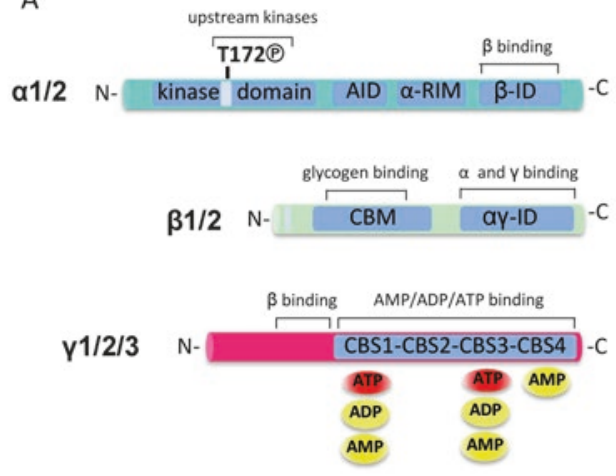

B

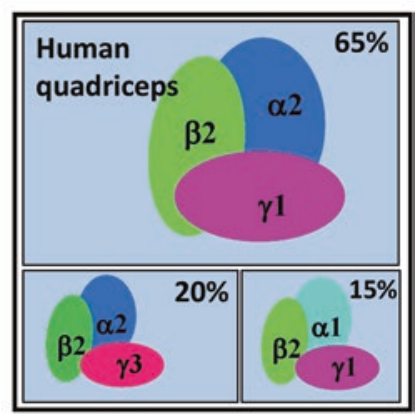

Fig. 1 Schematic representation of AMPK subunit. (a) AMPK domain structure. (b) AMPK heterotrimer composition in human skeletal muscle

\section{AMPK: Structure and Regulation}

AMPK is a heterotrimeric complex composed of one catalytic $\alpha$-subunit comprising a typical Ser/Thr kinase domain, in combination with scaffolding $\beta$-subunit containing a carbohydrate binding module $(\mathrm{CBM})$ and $\gamma$-subunit containing four cystathionine- $\beta$-synthase (CBS) domains that serve to bind adenine nucleotides (Fig. 1). Each of these subunits has several isoforms encoded by different genes $(\alpha 1$, $\alpha 2, \beta 1, \beta 2, \gamma 1, \gamma 2$ and $\gamma 3$ ) that can theoretically combine to form 12 possible heterotrimeric complexes (Hardie et al. 2012). Differential expression of the AMPK isoform in tissues and post-translational modifications that may locate AMPK in different cellular compartments also contribute to the specialized functions of AMPK heterotrimeric complexes. Of interest, in contrast to other AMPK isoforms, expression of the AMPK $\gamma 3$ isoform is restricted to the fast-twitch glycolytic skeletal muscle, suggesting a particular role for AMPK $\gamma 3$-containing complexes to handle metabolic challenges in skeletal muscle (Barnes et al. 2004). Mutation in the gene encoding for the AMPK $\gamma 3$ subunit PRKAG3 has been reported in pigs and humans, causing increased deposition of glycogen in skeletal muscle (Milan et al. 2000; Costford et al. 2007). In human skeletal muscle, only three heterotrimeric complexes have been detected, $\alpha 2 \beta 2 \gamma 1$ (65\% of the total pool), $\alpha 2 \beta 2 \gamma 3$ (20\%), and $\alpha 1 \beta 2 \gamma 1$ (15\%) (Birk and Wojtaszewski 2006; Fig. 1). The heterotrimer combination varies in mouse skeletal muscle, with the detection of five complexes, including $\alpha 1$ and $\alpha 2$-associated AMPK complexes with both $\beta 1$ and $\beta 2$ isoforms (Treebak et al. 2009). Interestingly, each heterotrimer combination displays a distinct activation profile in response to physical exercise, with $\gamma 3$-containing complexes being predominantly activated and $\alpha 2 \beta 2 \gamma 1$ and $\alpha 1 \beta 2 \gamma 1$ heterotrimers being unchanged or activated only after prolonged exercise (Birk and Wojtaszewski 2006).

The mechanism of AMPK activation involves two steps, a reversible phosphorylation at a conserved residue (Thr174 in $\alpha 1$ and Thr172 in $\alpha 2$ catalytic subunit, 
hereafter referred to as Thr172) within the activation loop in the $\alpha$-subunit, and a stimulatory allosteric effect upon binding of AMP within the CBS domains of the $\gamma$-subunit (Hardie et al. 2012). Activity of the complex increases more than 100-fold when AMPK is phosphorylated on Thr172 by identified upstream kinases. The combined effect of phosphorylation on Thr172 and allosteric regulation causes a $>1000$-fold increase in kinase activity, allowing high sensitivity in responses to small changes in cellular energy status. In addition, AMP and ADP binding regulates AMPK activity by promoting Thr172 phosphorylation by the upstream kinases and by protecting Thr172 from dephosphorylation by phosphatases. All the binding effects of AMP and ADP are antagonized by binding of ATP, providing a very sensitive mechanism for the activation of AMPK in conditions of cellular energy stress. Recent crystallographic studies of full-length AMPK heterotrimeric complexes have provided insights into the domain structure and the regulation upon binding of adenosine nucleotides (Hardie et al. 2016). Because the activating ligand is bound on the $\gamma$ subunit and the kinase domain is in the $\alpha$ subunit, intersubunit communication has to occur when switching to fully active states. Important regulatory features for this conformational switch are provided by $\alpha$ subunit flexible components (Fig. 1), the autoinhibitory domain (AID) and the $\alpha$-regulatory subunit interacting motif $(\alpha$-RIM)/ $\alpha$-hook interacting with the exchangeable nucleotide-binding sites on the $\gamma$ subunit, offering a signaling mechanism for nucleotide allosteric regulation and protection against dephosphorylation of AMPK heterotrimeric complex.

In mammals, the major upstream kinases are the liver kinase B1 (LKB1) and $\mathrm{Ca} 2+/$ calmodulin-dependent protein kinase kinase 2 (CaMKK2; Hardie et al. 2012). Interestingly, CaMKK2 has been shown to phosphorylate and activate AMPK in response to an increase in intracellular $\mathrm{Ca}^{2+}$ concentration, independent of any change in cellular AMP:ATP or ADP:ATP ratios. In skeletal muscle, the major upstream kinase phosphorylating $\alpha$ subunit Thr172 is liver kinase B1 (LKB1), as exercise-induced AMPK phosphorylation is prevented in mouse models lacking LKB1 (Sakamoto et al. 2005; Thomson et al. 2007). However, CaMKK $\beta$ has been shown to activate AMPK during mild tetanic skeletal muscle contraction (Jensen et al. 2007) and to increase AMPK $\alpha 1$ activity in response to skeletal muscle overload in LKB1-deficient mice (McGee et al. 2008).

\section{AMPK: Regulation by Hormones and Nutrients}

Although AMPK was originally identified as a sensor of cellular energy status by coordinating anabolic and catabolic pathways to balance nutrient supply with energy demand, it is now clear that it also participates in controlling whole-body energy homeostasis by integrating hormonal and nutritional signals from the cellular environment and the whole organism. Hypothalamic AMPK has been suggested to be a key mediator in the regulation of neuronal regulation of feeding behaviour and energy balance (Fig. 2). Inhibition of AMPK by expressing a dominant negative isoform in the arcuate nucleus (ARC) of the hypothalamus decreases mRNA 
Fig. 2 Hypothalamic AMPK in the regulation of energy balance

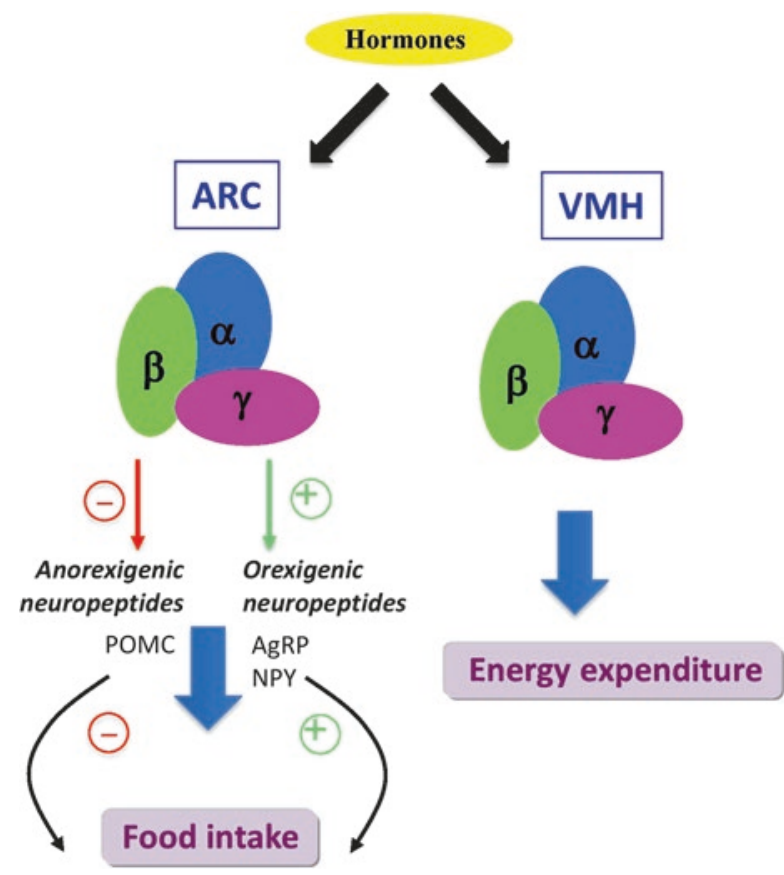

expression of the orexigenic neuropeptides agouti-related peptide (AgRP) and neuropeptide Y (NPY; Minokoshi et al. 2004). Conversely, activation of AMPK in the ARC by expressing a constitutively active AMPK form can further increase the fasting-induced expression of AgRP and NPY and then elevated feeding (Minokoshi et al. 2004). Similarly, starvation induces AMPK activation and food intake. In contrast, refeeding and glucose administration promote AMPK inactivation, accompanied by increased levels of anorexigenic neuropeptides proopiomelanocortin (POMC) and reduced levels of orexigenic neuropeptides AgRP mRNA in the ARC, highlighting the sensing levels of nutrients in the hypothalamus (Andersson et al. 2004; Minokoshi et al. 2004). There are also a number of hormones involved in the regulation of appetite that alter AMPK activity in the hypothalamus. For example, the orexigenic hormones, such as ghrelin and adiponectin, activate AMPK in the ARC and promote food intake (Andersson et al. 2004; Kubota et al. 2007); in contrast, anorectic hormones, such as leptin and oestradiol, inhibit AMPK in the ARC and inhibit food intake (Yang et al. 2011; Martinez de Morentin et al. 2014). Another layer of signal integration for the regulation of whole-body energy balance happens at the level of the ventromedial nucleus (VMH) of the hypothalamus, where AMPK regulates energy expenditure by controlling brown adipose tissue (BAT) thermogenesis (López et al. 2010; Whittle et al. 2012; Beiroa et al. 2014; Martinez de Morentin et al. 2014). Importantly, expression of a constitutively active AMPK form in the $\mathrm{VMH}$ is associated with a specific reduction in the expression of BAT thermogenic markers. In contrast, inhibition of AMPK by administration of thyroid hormone T3 to the $\mathrm{VMH}$ promotes whole body energy expenditure by triggering BAT 
thermogenesis via activation of the sympathetic nervous system (López et al. 2010). More recently, it was found that injection of glucagon-like peptide-1 (GLP-1) receptor agonist liraglutide into VMH decreased AMPK activity, stimulated expression of thermogenic markers in BAT, and promoted weight loss without affecting food intake (Beiroa et al. 2014). Overall these findings demonstrate a key role for central AMPK in the regulation of energy balance by influencing food intake and energy expenditure in response to peripheral signals, such as hormones and nutrients.

\section{AMPK: Regulation by Exercise}

Lifestyle intervention such as regular physical exercise is widely recognized to improve whole-body performance and metabolism in health and disease. An increase in daily physical activity is an effective approach to combat many disease symptoms associated with metabolic syndrome. Endurance exercise can improve insulin sensitivity and metabolic homeostasis. However, our understanding of how exercise exerts these beneficial effects is incomplete. In response to exercise, ATP turnover is increased by more than 100-fold (Gaitanos et al. 1993), resulting in increased ATP consumption and a rise in intracellular AMP levels due to the adenylate kinase reaction. These changes in the adenylate energy charge lead to the activation of AMPK in an intensity- and time-dependent manner, as shown in rodents (Winder and Hardie 1996) and in human muscle (Wojtaszewski et al. 2000). Once activated, AMPK regulates multiple signaling pathways whose overall effects are to increase ATP production, including fatty acid oxidation and glucose uptake. Given that AMPK is at the nexus of metabolic signaling pathways, a great deal of interest has focused on the role of AMPK in the adaptation of skeletal muscle to exercise as well as its use as a possible therapeutic target for the treatment of type 2 diabetes.

\section{Control of Exercise-Induced Glucose Transport}

During exercise, contracting skeletal muscle rapidly increases glucose uptake in an intensity-dependent manner to sustain the energy demand caused by increased ATP turnover. The first compelling evidence for a role for AMPK in regulating glucose uptake in skeletal muscle has been obtained with pharmacological activation of AMPK by AICAR (Merrill et al. 1997). This finding was further supported by the observation of impaired response to AICAR stimulation in mice expressing a dominant negative AMPK form in skeletal muscle (Mu et al. 2001). However, the role for AMPK in regulating glucose uptake during muscle contractile activity remains controversial and no solid genetic evidence has been put forward. Exercise-induced muscle glucose uptake is impaired in AMPK $\beta 1 \beta 2 \mathrm{M}-\mathrm{KO}$ mice but remains intact in AMPK $\alpha$ mdKO (O'Neill et al. 2011; Lantier et al. 2014). The reason for the 


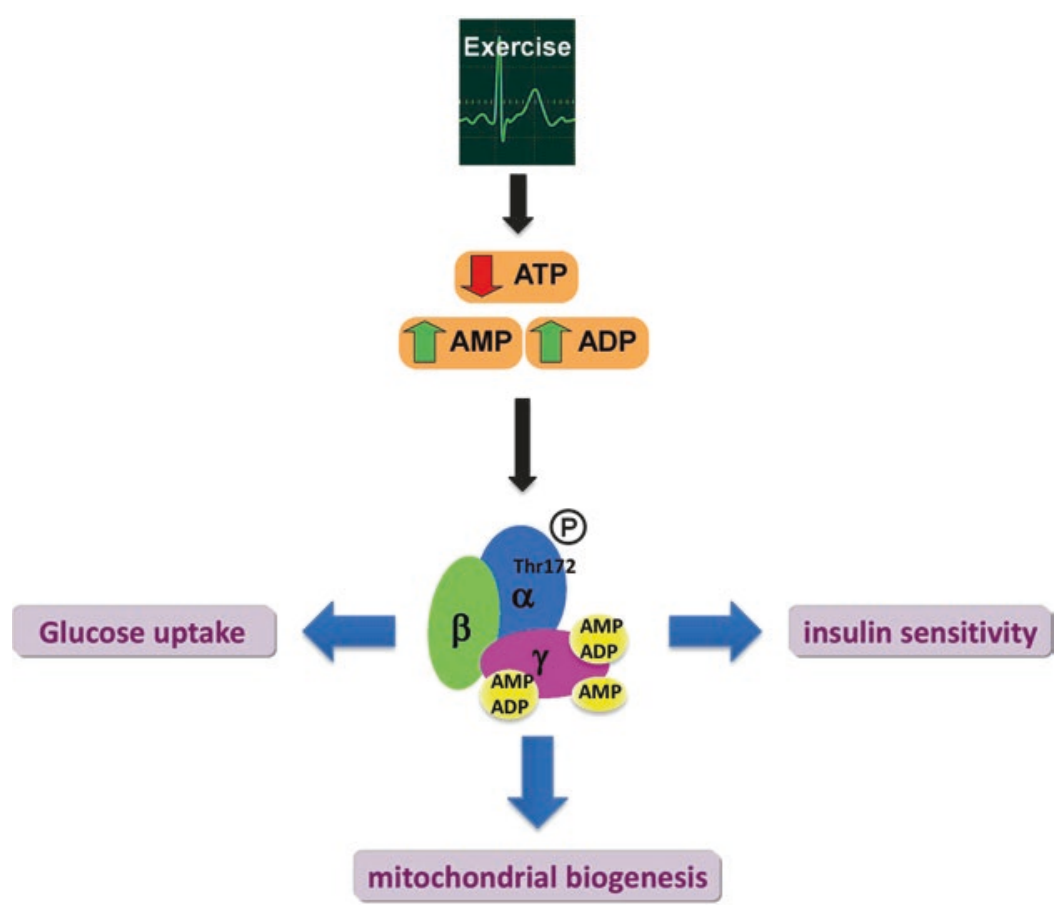

Fig. 3 AMPK-mediated regulation of skeletal muscle adaptation to exercise

difference between studies is not clear and future studies using inducible mouse models to study the role of AMPK in developed adult skeletal muscle are warranted.

It has been suggested that AMPK enhances glucose uptake by increasing the translocation of glucose transporter type 4 (GLUT4) to the plasma membrane (Fig. 3). Recent findings using AMPK-deficient mouse models have shown a convergence to the phosphorylation of the downstream target of TBC1D1, Rab-GTPase activating protein, which is emerging as an essential player in contraction-stimulated GLUT4 translocation (Stockli et al. 2015). In support of this finding, mice expressing TBC1D1 that mutated at predicted AMPK phosphorylation sites showed reduced contraction-stimulated glucose uptake (Vichaiwong et al. 2010). Interestingly, in exercised human skeletal muscle, TBC1D1 phosphorylation was significantly correlated with the activity of the $\alpha 2 \beta 2 \gamma 3$ heterotrimer, supporting the idea that AMPK is a direct upstream TBC1D1 kinase (Treebak et al. 2014).

Recent studies using compound 991, a cyclic benzimidazole derivative and potent direct AMPK activator, have shown that pharmacological activation of AMPK is sufficient to elicit metabolic effects in muscle appropriate for treating type 2 diabetes (Lai et al. 2014). It is also important to note that AMPK-mediated glucose uptake is not impaired in type 2 diabetes during exercise (Musi et al. 2001); therefore, activation of AMPK represents an attractive target for intervention. 


\section{Control of Training-Induced Muscle Adaptations}

In response to repeated metabolic stress, AMPK orchestrates a coordinated response to enhance mitochondrial biogenesis to match substrate utilization to demand (Fig. 3; Zong et al. 2002). This response is mediated through the regulation of peroxisome proliferator-activated receptor $\gamma$ co-activator- $1 \alpha$ (PGC- $1 \alpha$ ), a transcriptional co-activator that promotes the expression of mitochondrial genes encoded in both nuclear and mitochondrial DNA. AMPK activation causes the stimulation of PGC- $1 \alpha$ expression by direct phosphorylation, which drives expression from its own promoter but also involves deacetylation of PGC- $1 \alpha$ via the silent mating-type information regulator 2 homolog 1 (SIRT1; McGee and Hargreaves 2010). This finding was further supported by the increase seen in PGC- $1 \alpha$ and mitochondrial function in mice expressing a constitutively active AMPK form in skeletal muscle (Garcia-Roves et al. 2008). Moreover, deletion of AMPK greatly reduced exerciseinduced SIRT1-dependent activation of PGC-1 $\alpha$ signaling in skeletal muscle (Canto et al. 2010). Consistent with these findings, reduced muscle AMPK activity has been associated with decreased mitochondrial content during aging (Reznick et al. 2007) and in skeletal muscle from AMPK $\beta 1 \beta 2$ - and LKB1-deficient mice (O'Neill et al. 2011; Tanner et al. 2013).

\section{Control of Muscle Insulin Sensitivity}

Skeletal muscle demonstrates increased insulin-stimulated glucose uptake in the period after exercise (Richter et al. 1982). It may involve an increased translocation of GLUT4 at the plasma membrane in response to insulin. The underlying mechanism appears to involve AMPK-dependent phosphorylation of the Rab-GTPase TBC1D4 regulating GLUT4 translocation (Kjobsted et al. 2016). These results are fully in line with previous findings showing that prior pharmacological AMPK activation by AICAR enhances insulin sensitivity in rat skeletal muscle with increased phosphorylation of TBC1D4 (Kjobsted et al. 2015). Thus, activation of AMPK in the recovery after exercise may be important for exercise-induced adaptations and may serve to enhance muscle insulin sensitivity (Fig. 3). These findings may be highly relevant for pharmacological interventions in the treatment of muscle insulin resistance.

\section{Conclusions and Therapeutic Perspectives}

In mammals, AMPK has emerged as a major energy sensor that integrates multiple extracellular and intracellular input signals to coordinate cellular energy balance. Targeted by nutritional and hormone signals, AMPK has a crucial role in the 
hypothalamus to regulate energy intake and energy expenditure. In skeletal muscle, AMPK has been identified as an important integrator of the metabolic changes that occur during physical exercise. Given these roles, AMPK is an obvious target for treatment of metabolic disorders such as obesity and diabetes. However, although pharmacological activation in peripheral organs is expected to provide therapeutic benefits, activating central AMPK could cause deleterious consequences, specifically on body weight control. Recent studies have highlighted the adverse metabolic consequence of AMPK activation throughout all tissues (Yavari et al. 2016). Thus, a better understanding of the precise role of AMPK in the cell and its effects at the whole-body level will be essential for delineating therapeutic strategies aimed at targeting AMPK.

\section{References}

Andersson U, Filipsson K, Abbott CR, Woods A, Smith K, Bloom SR, Carling D, Small CJ (2004) AMP-activated protein kinase plays a role in the control of food intake. J Biol Chem 279:12005-12008

Barnes BR, Marklund S, Steiler TL, Walter M, Hjalm G, Amarger V, Mahlapuu M, Leng Y, Johansson C, Galuska D, Lindgren K, Abrink M, Stapleton D, Zierath JR, Andersson L (2004) The 5'-AMP-activated protein kinase gamma3 isoform has a key role in carbohydrate and lipid metabolism in glycolytic skeletal muscle. J Biol Chem 279:38441-38447

Beiroa D, Imbernon M, Gallego R, Senra A, Herranz D, Villarroya F, Serrano M, Ferno J, Salvador J, Escalada J, Dieguez C, Lopez M, Fruhbeck G, Nogueiras R (2014) GLP-1 agonism stimulates brown adipose tissue thermogenesis and browning through hypothalamic AMPK. Diabetes 63:3346-3358

Birk JB, Wojtaszewski JF (2006) Predominant alpha2/beta2/gamma3 AMPK activation during exercise in human skeletal muscle. J Physiol 577:1021-1032

Canto C, Jiang LQ, Deshmukh AS, Mataki C, Coste A, Lagouge M, Zierath JR, Auwerx J (2010) Interdependence of AMPK and SIRT1 for metabolic adaptation to fasting and exercise in skeletal muscle. Cell Metab 11:213-219

Costford SR, Kavaslar N, Ahituv N, Chaudhry SN, Schackwitz WS, Dent R, Pennacchio LA, McPherson R, Harper ME (2007) Gain-of-function R225W mutation in human AMPKgamma(3) causing increased glycogen and decreased triglyceride in skeletal muscle. PLoS One 2:e903

Gaitanos GC, Williams C, Boobis LH, Brooks S (1993) Human muscle metabolism during intermittent maximal exercise. J Appl Physiol (1985) 75:712-719

Garcia-Roves PM, Osler ME, Holmstrom MH, Zierath JR (2008) Gain-of-function R225Q mutation in AMP-activated protein kinase gamma3 subunit increases mitochondrial biogenesis in glycolytic skeletal muscle. J Biol Chem 283:35724-35734

Hardie DG (2014) AMPK-sensing energy while talking to other signaling pathways. Cell Metab 20:939-952

Hardie DG, Ross FA, Hawley SA (2012) AMPK: a nutrient and energy sensor that maintains energy homeostasis. Nat Rev Mol Cell Biol 13:251-262

Hardie DG, Schaffer BE, Brunet A (2016) AMPK: An energy-sensing pathway with multiple inputs and outputs. Trends Cell Biol 26:190-201

Jensen TE, Rose AJ, Jorgensen SB, Brandt N, Schjerling P, Wojtaszewski JF, Richter EA (2007) Possible CaMKK-dependent regulation of AMPK phosphorylation and glucose uptake 
at the onset of mild tetanic skeletal muscle contraction. Am J Physiol Endocrinol Metab 292:E1308-E1317

Kjobsted R, Treebak JT, Fentz J, Lantier L, Viollet B, Birk JB, Schjerling P, Bjornholm M, Zierath JR, Wojtaszewski JF (2015) Prior AICAR stimulation increases insulin sensitivity in mouse skeletal muscle in an AMPK-dependent manner. Diabetes 64:2042-2055

Kjobsted R, Munk-Hansen N, Birk JB, Foretz M, Viollet B, Bjornholm M, Zierath JR, Treebak JT, Wojtaszewski JF (2016) Enhanced muscle insulin sensitivity after contraction/exercise is mediated by AMPK. Diabetes. pii: db160530

Kubota N, Yano W, Kubota T, Yamauchi T, Itoh S, Kumagai H, Kozono H, Takamoto I, Okamoto S, Shiuchi T, Suzuki R, Satoh H, Tsuchida A, Moroi M, Sugi K, Noda T, Ebinuma H, Ueta Y, Kondo T, Araki E, Ezaki O, Nagai R, Tobe K, Terauchi Y, Ueki K, Minokoshi Y, Kadowaki $\mathrm{T}$ (2007) Adiponectin stimulates AMP-activated protein kinase in the hypothalamus and increases food intake. Cell Metab 6:55-68

Lai YC, Kviklyte S, Vertommen D, Lantier L, Foretz M, Viollet B, Hallen S, Rider MH (2014) A small-molecule benzimidazole derivative that potently activates AMPK to increase glucose transport in skeletal muscle: comparison with effects of contraction and other AMPK activators. Biochem J 460:363-375

Lantier L, Fentz J, Mounier R, Leclerc J, Treebak JT, Pehmoller C, Sanz N, Sakakibara I, SaintAmand E, Rimbaud S, Maire P, Marette A, Ventura-Clapier R, Ferry A, Wojtaszewski JF, Foretz M, Viollet B (2014) AMPK controls exercise endurance, mitochondrial oxidative capacity, and skeletal muscle integrity. FASEB J 28:3211-3224

López M, Varela L, Vázquez MJ, Rodríguez-Cuenca S, González CR, Velagapudi VR, Morgan DA, Schoenmakers E, Agassandian K, Lage R, Martínez de Morentin PB, Tovar S, Nogueiras R, Carling D, Lelliott C, Gallego R, Oresic M, Chatterjee K, Saha AK, Rahmouni K, Diéguez C, Vidal-Puig A (2010) Hypothalamic AMPK and fatty acid metabolism mediate thyroid regulation of energy balance. Nat Med 16:1001-1008

Martinez de Morentin PB, Gonzalez-Garcia I, Martins L, Lage R, Fernandez-Mallo D, MartinezSanchez N, Ruiz-Pino F, Liu J, Morgan DA, Pinilla L, Gallego R, Saha AK, Kalsbeek A, Fliers E, Bisschop PH, Dieguez C, Nogueiras R, Rahmouni K, Tena-Sempere M, Lopez M (2014) Estradiol regulates brown adipose tissue thermogenesis via hypothalamic AMPK. Cell Metab 20:41-53

McGee SL, Hargreaves M (2010) AMPK-mediated regulation of transcription in skeletal muscle. Clin Sci (Lond) 118:507-518

McGee SL, Mustard KJ, Hardie DG, Baar K (2008) Normal hypertrophy accompanied by phosphoryation and activation of AMP-activated protein kinase alpha1 following overload in LKB1 knockout mice. J Physiol 586:1731-1741

Merrill GF, Kurth EJ, Hardie DG, Winder WW (1997) AICA riboside increases AMP-activated protein kinase, fatty acid oxidation, and glucose uptake in rat muscle. Am J Physiol 273:E1107-E1112

Milan D, Jeon JT, Looft C, Amarger V, Robic A, Thelander M, Rogel-Gaillard C, Paul S, Iannuccelli N, Rask L, Ronne H, Lundstrom K, Reinsch N, Gellin J, Kalm E, Roy PL, Chardon P, Andersson L (2000) A mutation in PRKAG3 associated with excess glycogen content in pig skeletal muscle. Science 288:1248-1251

Minokoshi Y, Alquier T, Furukawa N, Kim YB, Lee A, Xue B, Mu J, Foufelle F, Ferre P, Birnbaum MJ, Stuck BJ, Kahn BB (2004) AMP-kinase regulates food intake by responding to hormonal and nutrient signals in the hypothalamus. Nature 428:569-574

Mu J, Brozinick JT Jr, Valladares O, Bucan M, Birnbaum MJ (2001) A role for AMP-activated protein kinase in contraction- and hypoxia-regulated glucose transport in skeletal muscle. Mol Cell 7:1085-1094

Musi N, Fujii N, Hirshman MF, Ekberg I, Froberg S, Ljungqvist O, Thorell A, Goodyear LJ (2001) AMP-activated protein kinase (AMPK) is activated in muscle of subjects with type 2 diabetes during exercise. Diabetes 50:921-927 
O’Neill HM, Maarbjerg SJ, Crane JD, Jeppesen J, Jorgensen SB, Schertzer JD, Shyroka O, Kiens B, van Denderen BJ, Tarnopolsky MA, Kemp BE, Richter EA, Steinberg GR (2011) AMPactivated protein kinase (AMPK) betalbeta2 muscle null mice reveal an essential role for AMPK in maintaining mitochondrial content and glucose uptake during exercise. Proc Natl Acad Sci USA 108:16092-16097

Reznick RM, Zong H, Li J, Morino K, Moore IK, HJ Y, Liu ZX, Dong J, Mustard KJ, Hawley SA, Befroy D, Pypaert M, Hardie DG, Young LH, Shulman GI (2007) Aging-associated reductions in AMP-activated protein kinase activity and mitochondrial biogenesis. Cell Metab 5:151-156

Richter EA, Garetto LP, Goodman MN, Ruderman NB (1982) Muscle glucose metabolism following exercise in the rat: increased sensitivity to insulin. J Clin Invest 69:785-793

Sakamoto K, McCarthy A, Smith D, Green KA, Grahame Hardie D, Ashworth A, Alessi DR (2005) Deficiency of LKB1 in skeletal muscle prevents AMPK activation and glucose uptake during contraction. EMBO J 24:1810-1820

Stockli J, Meoli CC, Hoffman NJ, Fazakerley DJ, Pant H, Cleasby ME, Ma X, Kleinert M, Brandon AE, Lopez JA, Cooney GJ, James DE (2015) The RabGAP TBC1D1 plays a central role in exercise-regulated glucose metabolism in skeletal muscle. Diabetes 64:1914-1922

Tanner CB, Madsen SR, Hallowell DM, Goring DM, Moore TM, Hardman SE, Heninger MR, Atwood DR, Thomson DM (2013) Mitochondrial and performance adaptations to exercise training in mice lacking skeletal muscle LKB1. Am J Physiol Endocrinol Metab 305:E1018-E1029

Thomson DM, Porter BB, Tall JH, Kim HJ, Barrow JR, Winder WW (2007) Skeletal muscle and heart LKB1 deficiency causes decreased voluntary running and reduced muscle mitochondrial marker enzyme expression in mice. Am J Physiol Endocrinol Metab 292:E196-E202

Treebak JT, Birk JB, Hansen BF, Olsen GS, Wojtaszewski JF (2009) A-769662 activates AMPK beta1-containing complexes but induces glucose uptake through a PI3-kinase-dependent pathway in mouse skeletal muscle. Am J Physiol Cell Physiol 297:C1041-C1052

Treebak JT, Pehmoller C, Kristensen JM, Kjobsted R, Birk JB, Schjerling P, Richter EA, Goodyear LJ, Wojtaszewski JF (2014) Acute exercise and physiological insulin induce distinct phosphorylation signatures on TBC1D1 and TBC1D4 proteins in human skeletal muscle. J Physiol 592:351-375

Vichaiwong K, Purohit S, An D, Toyoda T, Jessen N, Hirshman MF, Goodyear LJ (2010) Contraction regulates site-specific phosphorylation of TBC1D1 in skeletal muscle. Biochem J 431:311-320

Whittle AJ, Carobbio S, Martins L, Slawik M, Hondares E, Vazquez MJ, Morgan D, Csikasz RI, Gallego R, Rodriguez-Cuenca S, Dale M, Virtue S, Villarroya F, Cannon B, Rahmouni K, Lopez M, Vidal-Puig A (2012) BMP8B increases brown adipose tissue thermogenesis through both central and peripheral actions. Cell 149:871-885

Winder WW, Hardie DG (1996) Inactivation of acetyl-CoA carboxylase and activation of AMPactivated protein kinase in muscle during exercise. Am J Physiol 270:E299-E304

Wojtaszewski JF, Nielsen P, Hansen BF, Richter EA, Kiens B (2000) Isoform-specific and exercise intensity-dependent activation of 5'-AMP-activated protein kinase in human skeletal muscle. J Physiol 528(Pt 1):221-226

Yang Y, Atasoy D, HH S, Sternson SM (2011) Hunger states switch a flip-flop memory circuit via a synaptic AMPK-dependent positive feedback loop. Cell 146:992-1003

Yavari A, Stocker CJ, Ghaffari S, Wargent ET, Steeples V, Czibik G, Pinter K, Bellahcene M, Woods A, Martínez de Morentin PB, Cansell C, Lam BY, Chuster A, Petkevicius K, Nguyen-Tu MS, Martinez-Sanchez A, Pullen TJ, Oliver PL, Stockenhuber A, Nguyen C, Lazdam M, O'Dowd JF, Harikumar P, Tóth M, Beall C, Kyriakou T, Parnis J, Sarma D, Katritsis G, Wortmann DD, Harper AR, Brown LA, Willows R, Gandra S, Poncio V, de Oliveira Figueiredo MJ, Qi NR, Peirson SN, McCrimmon RJ, Gereben B, Tretter L, Fekete C, Redwood C, Yeo GS, Heisler LK, Rutter GA, Smith MA, Withers DJ, Carling D, Sternick EB, Arch JR, Cawthorne MA, 
Watkins H, Ashrafian H (2016) Chronic activation of gamma2 AMPK induces obesity and reduces beta cell function. Cell Metab 23:821-836

Zong H, Ren JM, Young LH, Pypaert M, Mu J, Birnbaum MJ, Shulman GI (2002) AMP kinase is required for mitochondrial biogenesis in skeletal muscle in response to chronic energy deprivation. Proc Natl Acad Sci USA 99:15983-15987

Open Access This chapter is licensed under the terms of the Creative Commons Attribution 4.0 International License (http://creativecommons.org/licenses/by/4.0/), which permits use, sharing, adaptation, distribution and reproduction in any medium or format, as long as you give appropriate credit to the original author(s) and the source, provide a link to the Creative Commons license and indicate if changes were made.

The images or other third party material in this chapter are included in the chapter's Creative Commons license, unless indicated otherwise in a credit line to the material. If material is not included in the chapter's Creative Commons license and your intended use is not permitted by statutory regulation or exceeds the permitted use, you will need to obtain permission directly from the copyright holder.

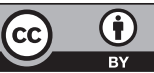

